\title{
Inundation Analysis Method for Urban Mountainous Areas Based on Soil Conservation Service Curve Number (SCS-CN) Model Using Remote Sensing Data
}

\author{
Xinyue He, ${ }^{1}$ Chao Chen, ${ }^{*}$ Yue Liu, ${ }^{2}$ and Yanli $\mathrm{Chu}^{3}$ \\ ${ }^{1}$ College of Marine Science and Technology, Zhejiang Ocean University, Zhoushan 316022, China \\ ${ }^{2}$ Jinling College, Nanjing University, Nanjing 210000, China \\ ${ }^{3}$ School of Economics and Management, Zhejiang Ocean University, Zhoushan 316022, China
}

(Received January 15, 2020; accepted April 25, 2020)

Keywords: SCS-CN model, inundation analysis, land use, urban mountain, rainfall-runoff calculation

Flooding and waterlogging are frequent disasters that pose serious threats to the safety of human lives and infrastructure. We propose a method of estimating the inundation area in urban mountainous zones based on the soil conservation service curve number (SCS-CN) model. Remote sensing data are used to localize parameters and ensure model accuracy, and are combined with topographic maps to determine land-use type, slope, and waterlogged ground. Watershed analysis based on the SCS-CN model is performed to obtain rainfall-runoff data. The inundation area is then estimated from the rainfall data, and the spatial and temporal distribution characteristics of the flood inundation area are analyzed from the perspective of land use. Experimental results from a case study in Mingxi, China, verify the effectiveness of this method for the analysis of flood inundation in urban mountainous areas.

\section{Introduction}

China experiences more severe natural disasters than most countries, ${ }^{(1)}$ and significant economic loss and human casualties due to natural disasters are higher in China than worldwide averages. $^{(1,2)}$ China frequently encounters flood and waterlogging disasters, which are sudden and destructive and cause heavy losses to urban safety, industrial and agricultural production, and residents. ${ }^{(3,4)}$

A flood is a phenomenon in which the water level of a river and/or lake rises in a short period of time to the point that it overflows into areas that normally have no water. ${ }^{(1)}$ Flood inundation analysis is an important part of flood prevention, and its timeliness and precision are crucially related to disaster reduction. ${ }^{(5,6)}$ Flood inundation analysis is typically implemented using hydrological basin models to simulate the flood flow area on the basis of the water body's fluid characteristics. ${ }^{(7,8)}$ These models include the soil conservation service curve number $(\mathrm{SCS}-\mathrm{CN})$ model, ${ }^{(9)}$ soil and water assessment tool (SWAT) ${ }^{(10)}$ erosion productivity impact calculator (EPIC) ${ }^{(11)}$ hydrologic modeling system (HEC-HMS), ${ }^{(12)}$ FloodArea model, ${ }^{(13)}$ and

*Corresponding author: e-mail: chenchao@zjou.edu.cn

https://doi.org/10.18494/SAM.2020.2769 
TOPMODEL ${ }^{(14)}$ which perform flood inundation analysis by calculating surface runoff using rainfall and supporting data (e.g., soil type, slope, vegetation coverage, and land-use type). ${ }^{(15,16)}$ The SCS-CN model has been widely used because of its reasonable and basic hypothesis and simple structure..$^{(9,15,16)}$ The curve number $(\mathrm{CN})$ of the SCS-CN model, provided by a CN table, is the only comprehensive parameter related to soil type, antecedent moisture condition (AMC), land-use type, slope, and other factors. ${ }^{(9,15,16)}$ However, this table is obtained from statistical and genetic analyses based on the physical geography and hydrometeorological conditions of the United States. The CN must therefore be localized to ensure the accuracy of flood inundation analysis generated by the SCS-CN model in a specific basin.

Remote sensing technology offers a range of advantages for data acquisition (e.g., collection of all-weather, all-directional, multiplatform, multispectral, multialtitude, multiangle, multitemporal, and multispatial data) that can accurately reflect land-use and morphological changes. $^{(3,4,17-19)}$ To quantitatively analyze rainfall-runoff characteristics and obtain more accurate flood inundation area estimates, we propose a new method of flood inundation analysis based in the SCS-CN model using remote sensing data. We test the validity of our method in the region of Mingxi, China. The results presented here provide a new method and data for accurately assessing the range of flood inundation and risk in urban mountainous areas.

\section{Materials and Methods}

\subsection{Study area}

Mingxi is located in northwest Fujian province in China $\left(26^{\circ} 08^{\prime}-26^{\circ} 39^{\prime} \mathrm{N}, 116^{\circ} 47^{\prime}-117^{\circ} 35^{\prime}\right.$ E) with an area of $1705.6 \mathrm{~km}^{2}$ (Fig. 1). ${ }^{(20)}$ There is a large difference in elevation from the north (high) to the south (low). The terrain is mainly mountainous or hilly, accounting for $91.91 \%$ of the total area, with a few plains $(6.98 \%){ }^{(15)}$

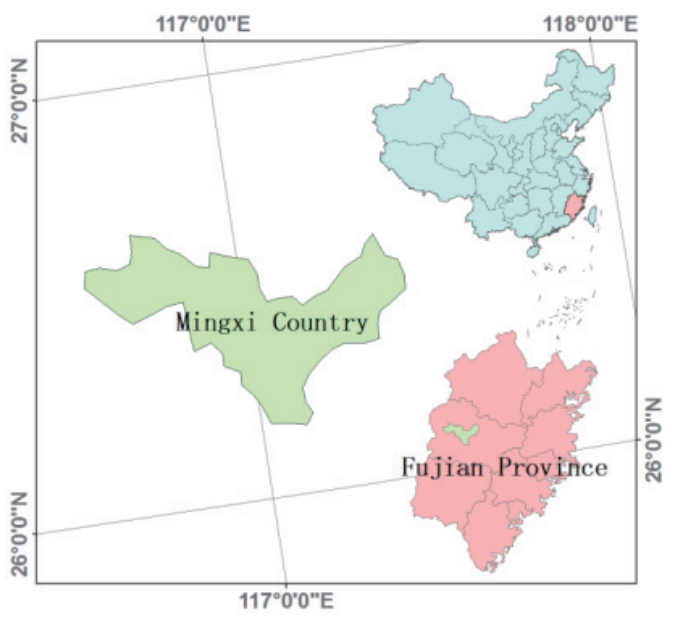

Fig. 1. (Color online) Study area: Mingxi, China. 


\subsection{Data}

The data used in this study include satellite remote sensing images, digital evaluation models (DEMs), administrative maps, and rainfall data of the study area (Table 1). Among them, the satellite remote sensing images were classified to extract land-use type, the DEM data were used for slope and hydrological analyses, and the rainfall data were used for runoff calculations using the SCS-CN model.

\subsection{Methods}

The SCS-CN model requires appropriate parameter selection according to land-use type, terrain, and parameter localization. ${ }^{(21,22)}$ The flood inundation analysis method proposed here is divided into three steps: data pre-processing, rainfall-runoff calculation based on the SCS-CN model, and flood inundation analysis. The specific technical route is shown in Fig. 2.

\subsubsection{Data pre-processing}

The inundation area is closely related to the land-use type, topography, and AMCs, all of which require pre-processing. The geometric correction and image classification of the satellite remote sensing data are performed to obtain the land-use type (e.g., cultivated land, garden, woodland, urban/rural construction land, transportation construction land, water, grassland, natural reserves, other agricultural land, and other construction land), and slope analysis is performed using the DEM data.

Table 1

Details of the data used in this study.

\begin{tabular}{|c|c|c|c|c|}
\hline Data & Type & Provider & Purpose & Description \\
\hline Landsat7 ETM+ & Raster & USGS & $\begin{array}{l}\text { For land-use } \\
\text { classification }\end{array}$ & $\begin{array}{l}\text { Launched on April 15, 1999, Landsat7 is } \\
\text { capable of acquiring remote sensing images } \\
\text { in six multispectral bands with } 30 \mathrm{~m} \text { spatial } \\
\text { resolution, one panchromatic band with } \\
15 \mathrm{~m} \text { spatial resolution, and one thermal } \\
\text { infrared band with } 60 \mathrm{~m} \text { spatial resolution. }\end{array}$ \\
\hline DEM & Raster & NASA & $\begin{array}{l}\text { For slope and } \\
\text { hydrological analyses }\end{array}$ & $\begin{array}{l}\text { The DEM with } 90 \mathrm{~m} \text { spatial resolution is } \\
\text { generated by the Shuttle Radar Topography } \\
\text { Mission (SRTM). }\end{array}$ \\
\hline Administrative maps & Vector & NGCC & For image cropping & $\begin{array}{l}\text { The vector data contain the boundary of } \\
\text { the study area at a scale of } 1: 50000 \text {. }\end{array}$ \\
\hline Rainfall data & Vector & CMA & For calculating runoff & $\begin{array}{l}\text { The rainfall data are the monthly averages } \\
\text { recorded by meteorological monitoring } \\
\text { stations. }\end{array}$ \\
\hline
\end{tabular}

ETM+: Enhanced thematic mapper plus

DEM: Digital elevation model

USGS: United States Geological Survey

NASA: National Aeronautics and Space Administration

NGCC: National Geomatics Center of China

CMA: China Meteorological Administration 


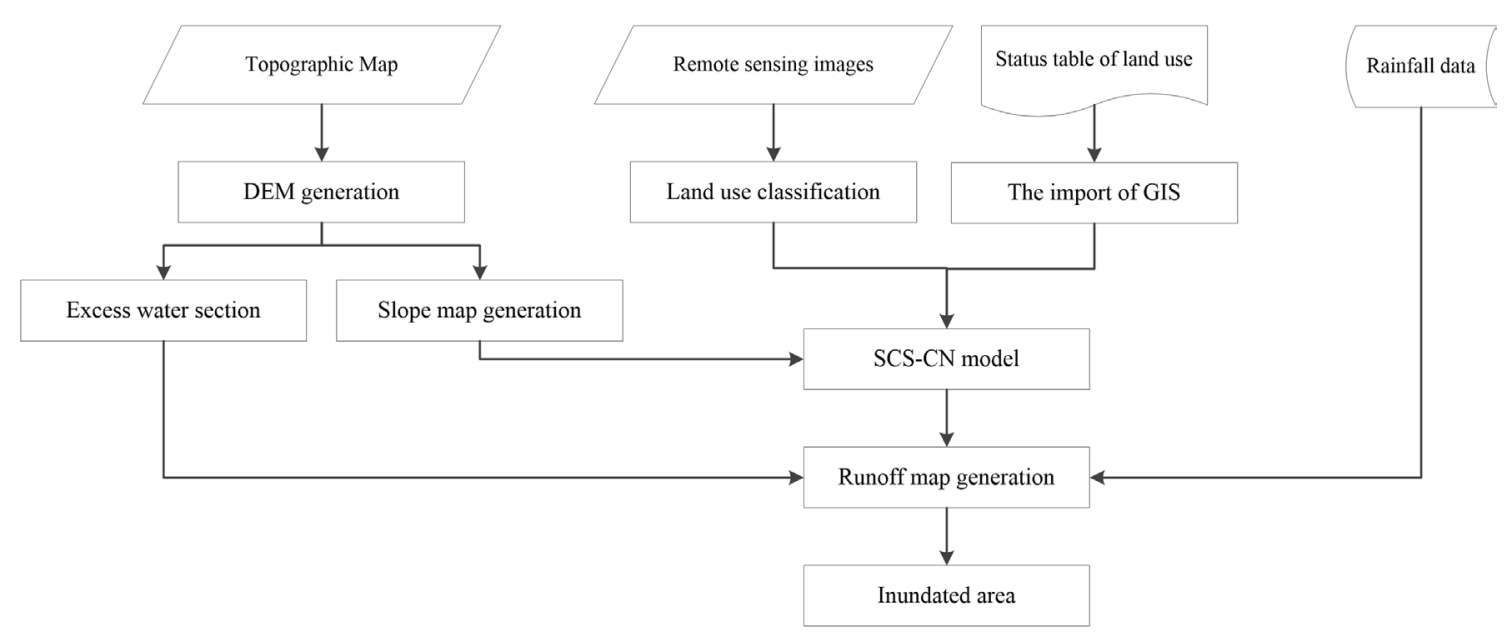

Fig. 2. Technology roadmap.

\subsubsection{Rainfall-runoff calculation}

The SCS-CN model proposed by the soil conservation service of the United States Department of Agriculture Soil Conservation Service comprehensively reflects the inundation range of a river network and water system by accounting for various factors (e.g., rainfall, soil type, land-use pattern, AMCs, and runoff)..$^{(9,15,16)}$ According to the infiltration capacity of different land-use types in different regions, the surface runoff of the region can be calculated to simulate the flood inundation range. ${ }^{(15,16)}$

The expression for surface runoff based on the SCS-CN model is as follows:

$$
Q=\frac{\left(P-I_{C}\right)^{2}}{P-I_{C}+S}
$$

where $Q, P, S$, and $I_{C}$ are surface runoff, total rainfall, rainwater consumption, and maximum possible retention, respectively, all in millimeters.

$I_{C}$ includes water absorption by trees, water storage in soil, and evaporation in air, ${ }^{(9)}$ and has the following relationship with $S$ :

$$
I_{C}=\lambda S,
$$

where $\lambda$ is the regional parameter, which mainly depends on geographical and climatic factors, and is usually 0.2 .

$S$ is a spatial variable related to soil texture, land use, slope, and other spatial factors, ${ }^{(9)}$ and is calculated as follows:

$$
S=\frac{25400}{C N}-254
$$


Among them, $\mathrm{CN}$ reflects the pre-rainfall soil and water conditions in the study area, and represents the maximum storage capacity of the soil. ${ }^{(23,24)}$ In this study, $\mathrm{CN}$ is calculated according to soil moisture, land-use type, and slope. Combined with the statistical yearbook issued for Mingxi, the preliminary wetting condition, land-use type, and slope data can be determined. ${ }^{(25,26)}$ From the $\mathrm{CN}$ table listed in the US National Engineering Manual, the CN range of this study was determined to be 53-87.

\subsubsection{Flood inundation analysis}

Flood inundation analysis was conducted using the runoff calculation based on the SCS-CN model and rainfall data. ${ }^{(27,28)}$ The runoff is related to water level, grid area, and grid elevation. The specific equation is as follows:

$$
Q=\sum_{i=1}^{n}\left(H-h_{i}\right) \times V
$$

where $Q$ is the regional runoff, $H$ is the flood level in the flood zone, $V$ is the grid area of each discrete unit in the grid model data, $h_{i}$ is the elevation of the $i$ th grid, and $n$ is the total number of grids.

\section{Results and Discussion}

Image classification, slope analysis, and hydrological analysis were performed using the satellite remote sensing data, DEM data, water body data, land-use type data, slope data, and river network data obtained from the study area. The pre-processing results are shown in Fig. 3.

Forest land occupies the largest area in Mingxi with water areas mostly located in the southeast and northwest. Urban and rural construction land, and transportation and water

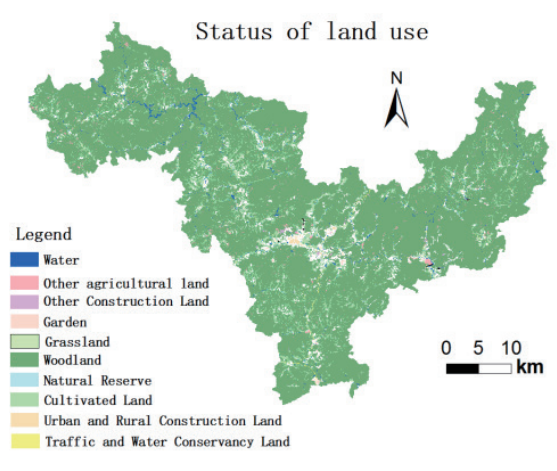

(a)

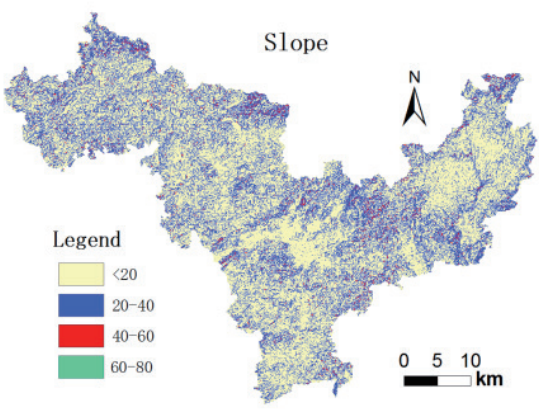

(b)

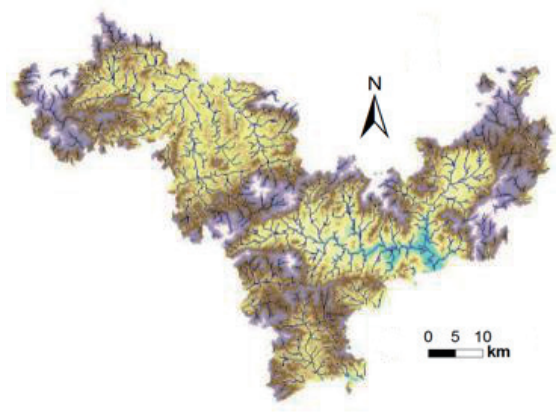

(c)

Fig. 3. (Color online) Image pre-processing results. (a) Land use and land cover of the study area. (b) Slope map. (c) River network. 
conservancy land are mostly located in central and southeast Mingxi. The high-altitude northwest contains steep slopes, whereas the southeast terrain is relatively flat with gentle slopes. The river network is affected by topographic partitioning and fractured with no coherent river system flowing through Mingxi.

Because the pre-precipitation soil moisture content and loss of vegetation root systems can affect runoff, the $\mathrm{AMC}^{(17)}$ is divided into three levels according to the antecedent precipitation index (API). These include levels A (drought), B (normal), and C (moist). The specific classification basis is shown in Table 2 .

Little rainfall and low water content are observed on the surface from December to January, a time that is prone to drought. From April to October, the surface water content is higher and vegetation growth is enhanced. The permeability of the 10 different land-use types is investigated and a $\mathrm{CN}$ is obtained for each land-use type (Fig. 4). The $\mathrm{CN}$ value of urban and rural construction land is relatively high with the worst infiltration effects and poor surface storage capacity. The $\mathrm{CN}$ values of cultivated land, garden, grassland, and natural reserve are similar. The $\mathrm{CN}$ of forest land is relatively high because of the loss of rain water and natural evaporation caused by tree canopies. Equation (1) is used with the precipitation data to calculate the runoff data of each month and land-use type, as shown in Fig. 5.

The surface runoff in Mingxi presents an increasing and decreasing trend with precipitation and is highest in April to August. From the land-use type analysis, runoff is determined to be highest in the natural reserves and lowest in the construction land.

Table 2

Classification of AMC in the study area.

\begin{tabular}{lccc}
\hline AMC & Growing period & Fallow period & Month \\
\hline Level A & $<36.2$ & $<13.9$ & $12,1,2,3$ \\
Level B & $36.2-54.6$ & $13.9-31.2$ & $7,8,9,10,11$ \\
Level C & $>54.6$ & $>31.2$ & $4,5,6$ \\
\hline
\end{tabular}

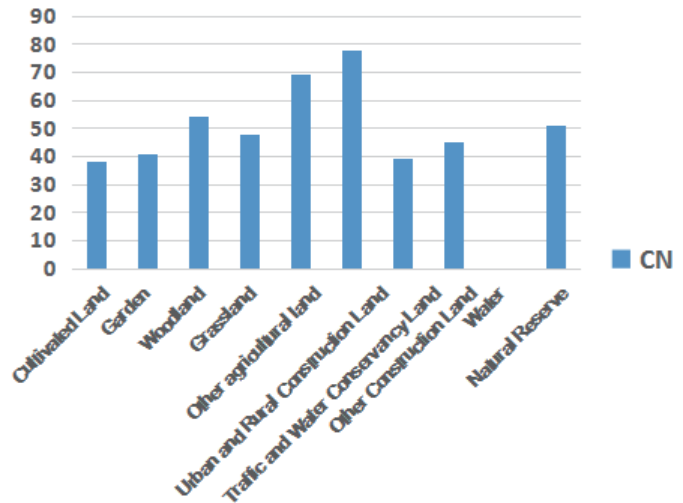

Fig. 4. (Color online) $\mathrm{CN}$ values of different land-use types.

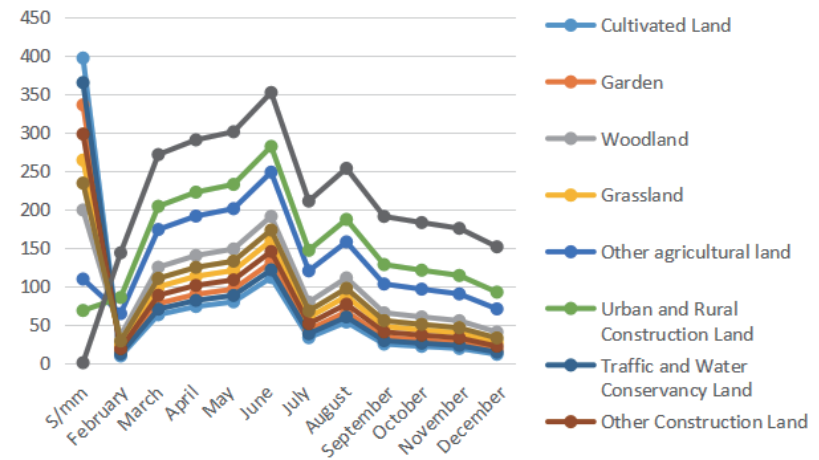

Fig. 5. (Color online) Surface runoff in 2016. 
The flooded area of Mingxi is simulated according to the surface runoff day over 12 months using the SCS-CN model. The results are shown in Fig. 6.
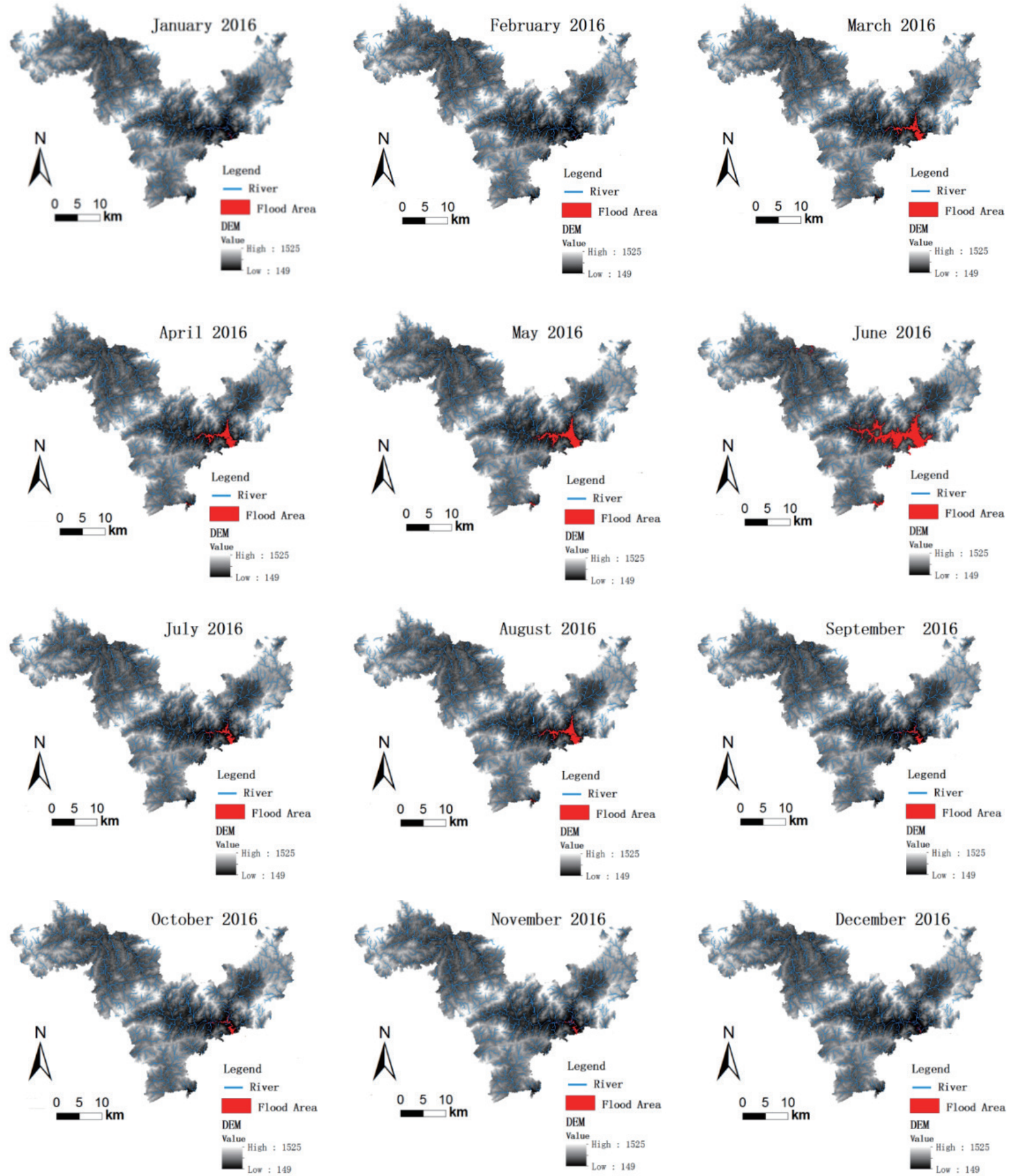

Fig. 6. (Color online) Results of inundation analysis of Mingxi, China, from January to December 2016. 
We use remote sensing data to localize $\mathrm{CN}$ and perform inundation analysis based on rainfall data using the SCS-CN model. According to the simulation results of the flooded areas, the main findings are as follows: (1) Precipitation is less in December and February, and the irrigation area located in the low-lying farmland faces severe drought. (2) Precipitation is greater from March to June, with a high possibility of a flood disaster. The inundation simulation figure shows that the inundation area is mainly located in southeastern and northwestern Mingxi. The terrain in the southeast is flat where residential areas are concentrated, and the river system is extensive and suitable for farmland irrigation. When rainfall is heavy, the water surface rises, frequently leading to flooding. Northwest of this area shows slightly higher elevations with steeper slopes that are prone to landslides, debris flow, and other disasters. (3) Analysis based on the land-use type revealed that the highest proportion of inundation area is accounted for by other agricultural land.

\section{Conclusions}

In this study, we consider the advantages of remote sensing technology that reflects surface morphological changes in both time and space. Parameter localization is achieved, and an inundation analysis method based on the SCS-CN model using remote sensing data is proposed. The main conclusions are as follows: (1) we have designed a technical process to analyze mountainous flood inundation areas based on the SCS-CN model; (2) we have analyzed simulations that show the risk and scope of flooding in Mingxi, China, for each month and land-use type.

Flood and waterlogging disasters are complex problems, and their analysis can be technically difficult. In this paper, we discuss the responses of various land-use types to flood inundation. We present an inundation analysis model by considering different data types and technical means, which can be useful for application to different river basins and environmental scenarios. Future studies will analyze the economic consequences of flood inundation using indicators such as gross national product.

\section{Acknowledgments}

This work was supported by the Fundamental Research Funds for Zhejiang Provincial Universities and Research Institutes (2019J00003), the National Natural Science Foundation of China (41701447), and the Training Program of Excellent Master Thesis of Zhejiang Ocean University.

\section{References}

1 H. Guo, L. Liu, L. Lei, Y. Wu, L. Li, B. Zhang, Z. Zuo, and Z. Li: Int. J. Digital Earth 3 (2010) 355. https://doi. org/10.1080/17538947.2010.532632

2 M. Domroes and D. Schaefer: Clim. Past Discuss. 4 (2008) 289. http://www.oalib.com/paper/2971833

3 C. Chen, J. Q. Fu, N. Lu, Y. L. Chu, J. C. Hu, B. Y. Guo, and X. Zhao: J. Indian Soc. Remote Sens. 47 (2019) 12. https://doi.org/10.1007/s12524-019-01036-Z 
4 C. Chen, J. Q. Fu, Y. Y. Gai, J. Li, L. Chen, V. S. Mantravadi, and A. H. Tan: IEEE Geosci. Remote Sens. Mag. 6 (2018) 3. https://doi.org/10.1109/MGRS.2018.2852804

5 S. I. Khan, Y. Hong, J. Wang, K. K. Yilmaz, J. J. Gourley, R. F. Adler, G. R. Brakenridge, F. Policelli, S. Habib, and D. Irwin: IEEE Trans. Geosci. Remote Sens. 49 (2011) 1. https://ieeexplore.ieee.org/document/5559412/ authors\#authors

6 P. D. Dao, N. T. Mong, and H. P. Chan: Geosci. Remote Sens. 56 (2019) 8. https://www.tandfonline.com/doi/ab s/10.1080/15481603.2019.1627062

7 F. Pappenberger, K. J. Beven, M. Ratto, and P. Matgen: Adv. Water Resour. 31 (2008) 1. https://www. sciencedirect.com/science/article/abs/pii/S0309170807000747

8 S. Siev, E. C. Paringit, C. Yoshimura, and S. Hul: River Res. Appl. 35 (2019) 9. https://onlinelibrary.wiley.com/ doi/abs/10.1002/rra.3491

9 S. K. Mishra and V. P. Singh: J. Hydrol. Eng. 4 (1999) 3. https://doi.org/10.1061/(ASCE)1084-0699(1999)4:3(257)

10 R. Jayakrishnan, R. Srinivasan, C. Santhi, and J. G. Arnold: Hydrol. Process. 19 (2005) 3. https://doi. org/10.1002/hyp.5624

11 J. R. Williams: Phil. Trans. R. Soc. Lond. B 329 (1990) 421. https://royalsocietypublishing.org/doi/10.1098/ rstb.1990.0184

12 M. R. Knebl, Z. L. Yang, K. Hutchison, and D. R. Maidment: J. Env. Manage. 75 (2005) 4.

13 C. C. Sampson, A. M. Smith, P. B. Bates, J. C. Neal, L. Alfieri, and J. E. Freer: Water Resour. Res. 51 (2015) 9. https://doi.org/10.1002/2015WR016954

14 K. Beven: Hydrol. Process. 11 (1997) 9. https://onlinelibrary.wiley.com/doi/epdf/10.1002/\%28SICI\%2910991085\%28199707\%2911\%3A9\%3C1069\%3A\%3AAID-HYP545\%3E3.0.CO\%3B2-O

15 S. K. Mishra, J. V. Tyagi, V. P. Singh, and R. Singh: J. Hydrol. 324 (2006) 1. https://www.sciencedirect.com/ science/article/pii/S0022169405004932

16 Z. H. Shi, L. D. Chen, N. F. Fang, D. F. Qin, and C. F. Cai: CATENA 77 (2009) 1. https://www.sciencedirect. com/science/article/abs/pii/S0341816208001768

17 S. Kaitwanidvilai, V. Chanarungruengkij, and P. Konghuayrob: Sens. Mater. 32 (2020) 2. https://myukk.org/ SM2017/article.php?ss=2428

18 D. B. Ji and J. C. Shi: IEEE J. Sel. Top. Appl. Earth Obs. Remote Sens. 7 (2014) 7. https://ieeexplore.ieee.org/ document/6727448/

19 X. Liu, S. Li, and X. Tong: IEEE J. Sel. Top. Appl. Earth Obs. Remote Sens. 11 (2018) 12. https://ieeexplore. ieee.org/document/8536398/

20 C. Liu, T. Xiong, P. Gong, and S. Qi: Remote Sens. Lett. 9 (2018) 1. https://www.tandfonline.com/doi/ref/10.10 80/2150704X.2017.1378454

21 J. Takahashi, K. Masato, S. Ito, N. Kaneko, W. Takahashi, T. Sakamoto, A. Shibata, and Y. Yu: Sens. Mater. 32 (2020) 2. https://myukk.org/SM2017/article.php?ss=2678

22 I. Portugués-Mollá, X. Bonache-Felici, J. F. Mateu-Bellésa, and J. B. Marco-Segurab: J. Hydrol. 541 (2016) 582. https://doi.org/10.1016/j.jhydrol.2016.05.048

23 S. Gajbhiye, S. K. Mishra, and A. Pandey: Appl. Water Sci. 4 (2013) 4. http://link.springer.com/article/10.1007/ s13201-013-0152-8

24 J. V. Tyagi, S. K. Mishra, R. Singh, and V. P. Singh: J. Hydrol. 352 (2008) 3. https://www.sciencedirect.com/ science/article/pii/S0022169408000656

25 J. F. Rosser, D. G. Leibovici, and M. J. Jackson: Nat. Hazards 87 (2017) 1. https://doi.org/10.1007/s11069-0172755-0

26 N. Kayet, K. Pathak, A. Chakrabarty, and S. Sahoo: Int. Soil Water Conserv. Res. 6 (2018) 1. https://doi. org/10.1016/j.iswcr.2017.11.002

27 Z. Zeng, G. Tang, Y. Hong, C. Zeng, and Y. Yang: Remote Sens. Lett. 8 (2017) 528. https://doi.org/10.1080/215 0704X.2017.1297544

28 M. Ajmal, G. Moon, J. Ahn, and T. Kim: J. Hydro-environ. Res. 9 (2015) 4. https://doi.org/10.1016/ j.jher.2014.11.003 


\section{About the Authors}

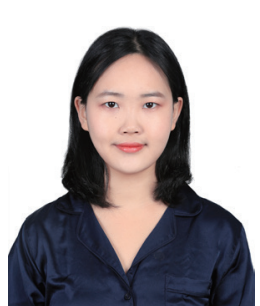

Xinyue He received her B.S. degree in geography information system in 2019 from Nanjing University, China. She is currently pursuing her M.S. degree in Zhejiang Ocean University. Her research interests include ocean surface chlorophyll inversion using high-spectral remote sensing image and remote sensing image analyses. Her supervisor is Dr. Chao Chen.

(yue_6457@163.com)

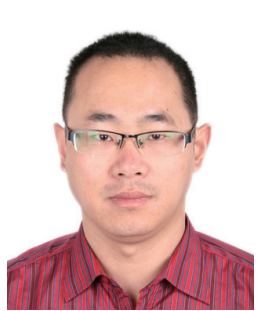

Chao Chen received his B.E. degree in telecommunications engineering in 2005 and his M.S. degree in photogrammetry and remote sensing in 2009, both from Shandong University of Science and Technology, Qingdao, China. He received his Ph.D. degree in cartography and geography information system from Peking University, Beijing, China, in 2013. He is currently an associate professor at Zhejiang Ocean University, Zhoushan, China. He mainly works on resolution remote sensing image analysis, pattern recognition, and data compression. (chenchao@zjou.edu.cn)

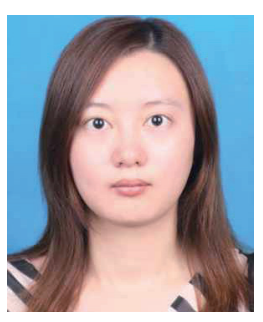

Yue Liu received her M.S. degree in geographic information system in 2012 from Nanjing University, China. Her main research direction is geographic information technology and applications. (gisnju@163.com)

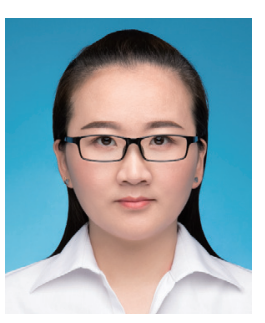

Yanli Chu received her M.E. degree in industrial design in 2014 from Guizhou Normal University, China. Her main research direction is information management. (chuyanli_shandong@163.com) 